\title{
Global fund changes tack on malaria therapy
}

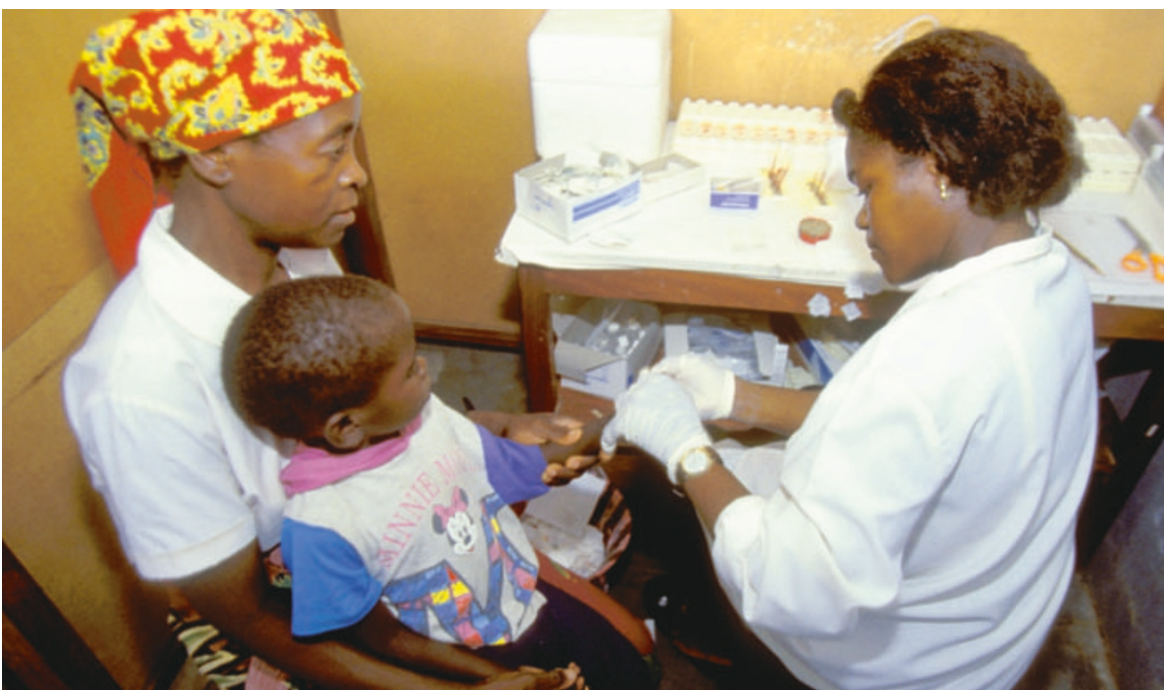

African patients currently receive drugs to which malaria is becoming resistant.

\section{Declan Butler, Paris}

An outcry from researchers has helped prompt a move to switch malaria treatment in Africa to a more effective therapy. The drug, artemisinin, comes from a Chinese herb, and cures $90 \%$ of patients in three days.

But aid donors have shrunk from promoting artemisinin, largely because it costs at least ten times more than established malaria treatments, to which the parasite that causes the disease has grown resistant.

At a closed meeting last month, the Geneva-based Global Fund to Fight AIDS, Tuberculosis and Malaria agreed to instruct African countries to retrospectively modify all malaria grants awarded to specify only the newer drug. The move will cost the fund more than a billion dollars over the next five years, says Vinand Nantulya, one of its senior officials.
All future funding will stipulate the use of artemisinin. The policy change is expected to force most countries to change their national drug policies. "Money talks," says Allan Schapira, coordinator of malaria policy and strategy at the Roll Back Malaria team of the World Health Organization (WHO).

Nantulya admits that the move was given "further impetus" by the discussion that followed publication of an article in The Lancet in January in which prominent scientists accused the fund and the WHO of "malpractice" for bowing to pressure from aid-giving countries. They also cautioned against the use of outdated drugs (Lancet363,237-240;2004).

Donors such as the United States and Britain had discouraged African countries from adopting artemisinin on the grounds that it cost too much, that data on its effect in children were insufficient, and that it was not needed in regions where other anti-malaria drugs still worked, says Amir Attaran of the Royal Institute of International Affairs in London, and the article's lead author.

In 2002, the WHO recommended artemisinin as the treatment of choice, but in Africa only Zambia and Zanzibar have adopted it.

The growing resistance of the malaria parasite Plasmodium falciparum to chloroquine and sulfadoxine-pyrimethamine, the mainstay of treatments in Africa - where $90 \%$ of global malaria deaths occur - has also damaged the lofty ambitions of the Roll Back Malaria initiative. This was launched in 1998, with the goal of halving malaria deaths by 2010 .

But deaths are up, not down, and mortality rates of treated patients are doubling in many parts of Africa. John Lidén, a spokesman for the Global Fund, says that it revisited resistance data from the WHO and other sources, and that this "composite set" convinced it to act. "We are results-based," he says, "and if we find we are paying for medicines that don't work, we want to pay for those that do."

The higher cost of artemisinin means that African countries will spend their revised grants more rapidly than they had intended. The drug costs about US\$2 for each adult treatment, compared with ten cents for existing drugs. Its price is expected to fall to about $\$ 1$ with improvements in production.

Countries might be allowed to apply for further grants in advance to make up the loss, Lidén says, and donors may be asked to release an additional $\$ 1$ billion to pay for the drug. "I appeal to the donor community to recognize that moving countries to using the right drugs will require much more money," says Nantulya, "They must take this seriously."

\section{Biotech industry struggles with generics approval}

Jonathan Knight, San Francisco

Leaders of the biotechnology industry hit out this week at the slowness of regulators in getting to grips with a problem that is confronting the industry as it comes of age: how to get approval for generic versions of biotech drugs after patents expire.

At the annual meeting of the Biotechnology Industry Organization (BIO) in San Francisco this week, industry managers and lawyers expressed frustration at not knowing what they have to do to get generics approved. "We don't know what the rules are," complains Meredith Manning, a regulatory lawyer at Washington, DC-based law firm Hogan \& Hartson, who represents biotech firms. This will considerably lengthen the time for cheaper generics to reach the market, she says.

Drug patents are now expiring 17 years after they were first filed. In the United States, generics need approval from the Food and Drug Administration (FDA). This is straightforward for most drugs, which have a single active ingredient - usually a small molecule - whose purity and composition can be confirmed by chemical testing.

But the drugs that the biotechnology industry has developed tend to be large molecules such as antibodies and other proteins, whose identities cannot be confirmed by a simple chemical analysis. Manufacturers of generic versions of these products will need to show equivalence with the original in another way. And the FDA has not yet said how this should be done.

Biotech generics are on sale now, but they have had to submit to costly new drug reviews, including clinical trials. Among the generics approved by this route are recombinant human insulin and the anti-cancer drug interferon-alpha. But dozens more biotech patents will expire in the next few years.

Janet Woodcock, director of the FDA's Center for Drug Evaluation and Research at Rockville, Maryland, says that the agency is working hard to have guidelines available for public review, perhaps later this year. "We fully intend to have a transparent process," she says. 